\title{
The role of the amino-terminal domain in the interaction of unliganded peroxisome proliferator-activated receptor $\gamma-2$ with nuclear receptor co-repressor
}

\author{
Sadako Suzuki, Shigekazu Sasaki, Hiroshi Morita, Yutaka Oki, Daisuke Turiya, \\ Takeshi Ito, Hiroko Misawa, Keiko Ishizuka and Hirotoshi Nakamura \\ Second Division, Department of Internal Medicine, Hamamatsu University School of Medicine, 1-20-1 Handayama, Higashi-ku, Hamamatsu, \\ Shizuoka 431-3192, Japan \\ (Correspondence should be addressed to S Sasaki; Email: sasakis @ hama-med.ac.jp)
}

\begin{abstract}
Peroxisome proliferator-activated receptor $\gamma$-2 (PPARG2) is a ligand-dependent transcriptional factor involved in the pathogenesis of insulin resistance. In the presence of a ligand, PPARG2 associates with co-activators, while it recruits co-repressors (CoRs) in the absence of a ligand. It has been reported that the interaction of liganded PPARG2 with co-activators is regulated by the amino-terminal A/B domain (NTD) via inter-domain communication. However, the role of the NTD is unknown in the case of the interaction between unliganded PPARG2 and CoRs. To elucidate this, total elimination of the influence of ligands is required, but the endogenous ligands of PPARG2 have not been fully defined. PPARG1-P467L, a naturally occurring mutant of PPARG1, was identified in a patient with severe insulin resistance. Reflecting its very low affinity for various ligands, this mutant does not have transcriptional activity in the PPAR response element, but exhibits dominant negative effects (DNEs) on liganded wild-type PPARG2-mediated transactivation. Using the corresponding PPARG2 mutant, PPARG2-P495L, we evaluated the role of the NTD in the interaction between unliganded PPARG2 and CoRs. Interestingly, the DNE of PPARG2-P495L was increased by the truncation of its NTD. NTD deletion also enhanced the DNE of a chimeric receptor, PT, in which the ligand-binding domain of PPARG2 was replaced with that of thyroid hormone receptor $\beta-1$. Moreover, NTD deletion facilitated the in vitro binding of nuclear receptor CoR with wild-type PPARG2, mutant P495L, and the PT chimera (PPARG2-THRB). Inter-domain communication in PPARG2 regulates not only ligand-dependent transactivation but also ligand-independent silencing.
\end{abstract}

Journal of Molecular Endocrinology (2010) 45, 133-145

\section{Introduction}

Peroxisome proliferator-activated receptor $\gamma$-2 (PPARG2) belongs to the nuclear hormone receptor (NHR) superfamily (Desvergne \& Wahli 1999, Michalik et al. 2006, Lu \& Cheng 2010). Through different promoter usage and splicing, the PPARG gene generates PPARG1, 2, and 3. PPARG2 is predominantly expressed in adipocytes and macrophages, and has profound effects on insulin sensitivity (Desvergne \& Wahli 1999). PPARGs heterodimerize with the retinoid $\mathrm{X}$ receptors (RXRs) on short DNA sequences, designated the PPARresponsive element (PPRE). PPRE consists of a pair of directly repeated half sites (typically AGGTCA) spaced with one random nucleotide (DR1; Desvergne \& Wahli 1999). Upon ligand binding, the PPARG2-RXR heterodimer recruits co-activators including members of the p160 protein family, CREB-binding protein/p300, and thyroid hormone receptor (THR)-associated protein 220 (Ge et al. 2002), resulting in transactivation (Perissi $\&$ Rosenfeld 2005). The function of the ligand-binding domain (LBD) is known to be modulated by the phosphorylation of a serine at codon 112 (S112) in the amino-terminal A/B domain (NTD) by mitogenactivated protein kinase (MAPK; Hu et al. 1996, Adams et al. 1997, Camp \& Tafuri 1997, Shao et al. 1998). Based on functional analyses of S112 phosphorylation, Shao et al. (1998) proposed 'inter-domain communication', where NTD controls the ligand-binding affinity of the LBD and recruitment of SRC-1, a member of the p160 family.

In the absence of a cognate ligand, THR $\alpha-1$ (THRA1), $\beta-1$ (THRB1), and retinoic acid receptor $\alpha$ (RARA) are known to interact with co-repressors (CoRs) including nuclear receptor CoR (NCoR) and silencing mediator of retinoic acid and THRs (SMRT), resulting in transcriptional silencing. The interaction of CoRs with unliganded PPARG2-LBD has been demonstrated in vitro (Zamir et al. 1997, Krogsdam et al. 2002, Lee et al. 2002, Stanley et al. 2003) and in vivo (Gurnell et al. 2000, Wang et al. 2004, Yu et al. 2005). RNA interference assays against the CoR genes (Guan et al. 2005, Yu et al. 2005) and chromatin immunoprecipitation assays (ChIP) suggest that PPARG2 associates with $\mathrm{CoR}$ in vivo and suppresses the basal transcriptional activity of PPARG2-target genes including glycerol kinase (Guan et al. 2005), oxidized low-density 
lipoprotein receptor 1 (Chui et al. 2005), aP2, and PPARG itself (Picard et al. 2004). However, there is no evidence that the NTD regulates the interaction of its LBD with CoR in the absence of a ligand.

Unlike THRs or RARA, studies using conventional reporter assays have failed to demonstrate the silencing function of unliganded PPARG2 (Zhang et al. 1999, Chatterjee 2001, Semple et al. 2006). In 293EBNA cells without the addition of an exogenous ligand, PPARG did not exhibit silencing function but rather constitutive activation of basal transcription (Barroso et al. 1999, Gurnell et al. 2003, Agostini et al. 2004, Semple et al. 2006). Additionally, overexpression of NCoR did not potentiate the suppression by PPARG2 of acyl-CoA oxidase-derived PPRE (Aox-PPRE) in 293T cells (Zamir et al. 1997). To detect the silencing effect of wild-type PPARG2 in a conventional reporter assay, it is necessary to maintain the majority of PPARG2 molecules in truly an unliganded condition. Endogenous ligands for PPARG2 are reported to be generated by 3T3-L1 preadipocytes (Kim et al. 1998, Camp et al. 2001, Madsen et al. 2003, Tzameli et al. 2004) and macrophages (Yano et al. 2007). Similar substances may also be generated by CV1 cells (DiRenzo et al. 1997, Werman et al. 1997), which have been often used in the studies of NHRs. Shi et al. (2002) reported that, in CV1 cells, 'unliganded' PPARG2 did not suppress ligand-induced transcription by PPAR $\alpha$ (PPARA). These putative ligand(s) for PPARG2 are predicted to dissociate CoR from PPARG2 (Gurnell et al. 2000, Wang et al. 2004, Yu et al. 2005).

Barroso et al. (1999) and Savage et al. (2003) reported two different heterozygous mutations, PPARG1-P467L and V290M, in patients with severe insulin resistance. Both mutants, PPARG1-P467L in particular, have very low affinity for the PPARG ligands and constitutively bind with CoR (Barroso et al. 1999, Agostini et al. 2004). They are believed to be resistant to the endogenous ligand since they exhibited no transactivation in 293EBNA cells in the absence of an exogenous ligand (Barroso et al. 1999, Agostini et al. 2004). These mutant PPARG1s also exhibited potent dominant negative effects (DNEs) on the ligand-induced transactivation by wild-type PPARG1 (Barroso et al. 1999). These properties are reminiscent of the DNE seen in mutant THRB1, identified in patients with resistance to thyroid hormones (RTH; Yoh et al. 1997, Chatterjee 2001), since mutant THRB1s lose their T3-binding activity due to amino acid substitutions in their LBD (Refetoff $e t a l$. 1993) and exhibit DNEs by continuous interaction with CoR (Yoh et al. 1997). DNEs against ligand-induced transactivation by wild-type PPARGs have been reported in artificially generated mutant PPARGs that mimic the amino acid substitution of mutant THRB1s in RTH (Zamir et al. 1997, Gurnell et al. 2000, Armoni et al. 2003, Park et al. 2003, Freedman et al. 2005).
Using the analogy of inter-domain communication in ligand-dependent transactivation involving PPARG2, we speculate that the NTD may regulate the interaction of CoR with the unliganded LBD. To confirm this, we took advantage of the fact that PPARG1-P467L has very low affinity for a variety of known ligands (Barroso et al. 1999, Kallenberger et al. 2003, Agostini et al. 2004). We examined the effect of NTD truncation on the DNE of PPARG2-P495L, which possesses an amino acid substitution corresponding to PPARG1-P467L (Barroso et al. 1999, Gurnell et al. 2003, Agostini et al. 2004, Semple et al. 2006). In addition, we generated a chimeric receptor, PT, by fusing the PPARG2-derived NTD and DNA-binding domain (DBD) to the THRBLBD in order to evaluate its NTD function. Our study demonstrates that the PPARG2-NTD functions to attenuate the association of CoR with unliganded LBD.

\section{Materials and methods}

\section{Plasmid construction}

A PT chimera was created by fusing the NTD, DBD, and the A- and T-boxes of mouse PPARG2 (codon 1-232) to the CoR box and LBD of human THRB1 (codon 192-461) using standard molecular techniques. An expression plasmid for mouse PPARG2-P495L was generated from pSG5-mouse PPARG2 using a sitedirected mutagenesis kit (Stratagene, La Jolla, CA, USA) in the same codon as used for human patients (Barroso et al. 1999). The construction of mutant THRB1, pCMX-hTHRB1-K443E, and tk-TREp-Luc is described elsewhere (Sasaki et al. 1995). Using the PCR with the PT chimera, PPARG2-P495L, and the THRB1K443E as templates, dNPT, PPARG2-dNP495L, and THRB1-dNK443E were generated respectively. In dNPT and PPARG2-dNP495L, the N-terminal 127 amino acids were truncated, while, in THRB1-dNK443E, the N-terminal 94 amino acids of THRB1-K443E were deleted. The AHT mutation in the CoR box of the THRB1 hinge domain (codon 263 Ala to Gly, codon 264 His to Gly, and codon $267 \mathrm{Thr}$ to Ala; Horlein et al. 1995) was generated with identical codons in the LBD of PT and dNPT to create PT-AHT and dNPT-AHT respectively. The validity of all plasmid constructs was confirmed by sequencing.

\section{Cell culture and transient transfection}

CV1 cells were maintained in DMEM supplemented with $10 \%$ FCS. Using the calcium phosphate precipitation method (Sasaki et al. 1995), 6-well dishes were transfected with $300 \mathrm{ng}$ of the luciferase reporter gene containing three copies of rat Aox-derived PPRE fused to thymidine kinase (tk-AoxPPRE-Luc), $1200 \mathrm{ng}$ of $\beta$-galactosidase expression vector (a modified version 
of pCH110), and expression plasmids for receptors in the quantities indicated in the figure legends. Empty vector ( $\mathrm{pCMX}$ or pSG5) was added to adjust the total amount of DNA. The reporter assay with hADRP-4k-Luc was performed using same protocol as tk-AoxPPRE-Luc. The pre-adipocyte cell line 3T3-L1 was maintained in DMEM with 10\% FCS. Using 12-well dishes, the cells were transfected by the lipofection method (Sasaki et al. 1999) with $300 \mathrm{ng}$ of tk-AoxPPRE-LUC reporter gene, plasmids for receptors, and $500 \mathrm{ng}$ of pRL-TK expression vector (Promega) to standardize transfection efficiency. The luciferase activity was normalized using $\beta$-galactosidase activity in CV1 cells or by pRL-TK activity in 3T3L1 cells. To evaluate DNE in CV1 and 3T3L1 cells, wild-type receptor plasmid was co-transfected with twofold molar excess of mutant receptor plasmid. All experiments were performed in duplicate and repeated more than three times.

\section{Gel shift assay}

Oligonucleotides containing the Aox-derived PPRE (sense; 5'-aggggaccaggacaaaggtcacgttcggg-3') were labeled with ${ }^{32} \mathrm{P}-\gamma$-ATP using T4 polynucleotide kinase (Toyobo, Osaka, Japan). Receptor proteins were translated using the TNT in vitro translation kit (Promega). The translated receptor proteins and ${ }^{32}$ P-labeled PPRE oligonucleotides $\left(5 \times 10^{4}\right.$ c.p.m.) were mixed and incubated for $20 \mathrm{~min}$ at room temperature. The reaction mixture was loaded onto $5 \%$ polyacrylamide gel. The gel was dried and visualized using the BAS-1000 autoradiography system (Fuji, Tokyo, Japan).

\section{GST pulldown assay}

Receptor proteins were generated using the TNT in vitro translation kit (Promega) in the presence of ${ }^{35}$ S-methionine. Bacterially expressed glutathione $S$-transferase (GST) protein fused to the receptor interacting domain of NCoR (GST-NCoR; Kawai et al. 2004) was immobilized on glutathione-Sepharose $4 \mathrm{~B}$ beads (Amersham Life Science). The beads were washed once with binding buffer ( $25 \mathrm{mM}$ HEPES, $\mathrm{pH} 7 \cdot 6,2 \mathrm{mM}$ dithiothreitol, $20 \mathrm{mM} \mathrm{NaCl}, 20 \%$ glycerol, $2 \mathrm{mg} / \mathrm{ml}$ BSA, and protease inhibitors $(0.3 \mathrm{mM}$ phenyl methylsulfonylfluoride, $1 \cdot 0 \mu \mathrm{g} / \mathrm{ml}$ leupeptin, and $2 \cdot 0 \mu \mathrm{g} / \mathrm{ml}$ aprotinin) ), before being mixed with binding buffer and left overnight at $4{ }^{\circ} \mathrm{C}$. ${ }^{35} \mathrm{~S}$-methionine-labeled in vitro translated receptor proteins were incubated with the GST fusion protein-bound beads for $3 \mathrm{~h}$ at $4{ }^{\circ} \mathrm{C}$. After the incubation, the beads were washed twice with $1 \mathrm{ml}$ of binding buffer $+0 \cdot 1 \%$ Triton X-100 and once with $1 \mathrm{ml}$ of $50 \mathrm{mM}$ Tris-HCl ( $\mathrm{pH} 8 \cdot 0$ ) buffer. The eluted proteins were resolved by SDS-PAGE and visualized by the BAS-1000 autoradiography system (Fuji).

\section{Statistical analysis}

Each experiment was performed in duplicate more than three separate times, and each result is expressed as the mean \pm s.D. The statistical significance was determined by the ANOVA and Fisher's protected least significant difference (PLSD) test using StatView 4.0 software (Abacus Concepts, Berkeley, CA, USA). $P<0 \cdot 05$ was considered significant.

\section{Results}

\section{The DNE of PPARG2-P495L is enhanced by the truncation of its NTD}

We generated the mutant PPARG2 by deleting its NTD (dNPPARG2; Fig. 1A) and transfecting it into CV1 cells. The expression level of dNPPARG2 was comparable with that of wild-type PPARG2 (Fig. 1B). In the presence of troglitazone, both wild-type PPARG2 and dNPPARG2 stimulated the luciferase reporter gene containing Aox-PPRE fused with the tk promoter (tk-AoxPPRELuc; Fig. 1C, lanes 2-5). Although the existence of constitutive activity in the PPARG2-NTD was reported (Werman et al. 1997), truncation of the NTD did not affect transactivation (Fig. 1C, lanes 3 and 5). Without the addition of troglitazone, wild-type PPARG2 and dNPPARG2 showed stimulated basal levels of tk-AoxPPRE-Luc activity (Fig. 1C, lanes 2 and 4), suggesting that they had no silencing effect. To exclude the influence of endogenous ligands contained in the CV1 cells (DiRenzo et al. 1997, Werman et al. 1997), we employed PPARG2-P495L, which has no ligand-binding ability due to its amino acid substitution corresponding to PPARG1-P467L, and compared it with its NTDtruncated mutant, PPARG2-dNP495L (Fig. 1A). The expression levels of PPARG2-P495L and dNP495L were comparable with that of wild-type PPARG2 (Fig. 1B). Both PPARG2-P495L and dNP495L completely lost their ligand-independent (Fig. 1C, lanes 1, 6, and 8) and ligand-dependent transactivation functions (lanes 7 and 9). Co-expression of a twofold excessive amount of PPARG2-P495L repressed the troglitazone-dependent transactivation induced by wild-type PPARG2 (lanes 3 and 10), suggesting the presence of a DNE caused by PPARG2-P495L. Remarkably, the DNE of PPARG2-dNP495L was much more potent than that of PPARG2-P495L (lanes 3, 10, and 11). Likewise, PPARG2-dNP495L exhibited a more rigorous DNE than PPARG2-P495L in 3T3L1 pre-adipocytes (Fig. 1D). Since removal of the NTD potentiates the DNE, the PPARG2-NTD may interfere with the DNE of PPARG2P495L. We tested the DNE on the activity of Aox-PPRE induced by liganded PPARG1. As shown in Fig. 2A, DNE by PPARG2-dNP495L was stronger than that by P495L (Fig. 2A), although its potency was milder than that on 


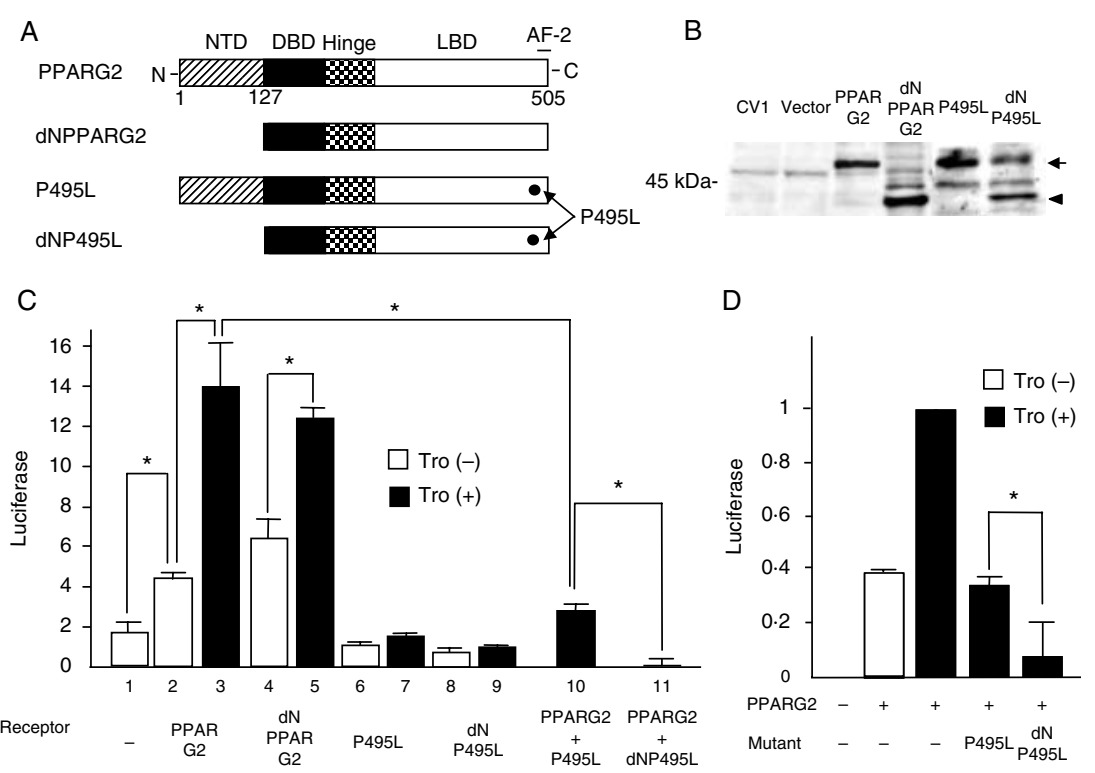

Figure 1 The effect of NTD truncation on the DNE of PPARG2-P495L. (A) A schematic representation of wild-type PPARG2, dNPPARG2, PPARG2-P495L, and PPARG2dNP495L. P495L, PPARG2-P495L; dNP495L, PPARG2-dNP495L; NTD, amino-terminal domain; DBD, DNA-binding domain; hinge, hinge domain; LBD, ligand-binding domain; AF-2, activation function 2. The arrows indicate the substitution of proline at codon 495 with leucine in PPARG2-P495L and dNP495L. The numbers below the schema represent the position in the amino acid sequence. The NTD encompassing the initiation methionine and histidine at codon 127 was truncated in dNPPARG2 and PPARG2-dNP495L. (B) The expression levels of PPARG2-P495L (arrow), dNPPARG2, and PPARG2-dNP495L (arrowhead) were comparable with that of wild-type PPARG2 (arrow). CV1 cells in $10 \mathrm{~cm}$ dish were transfected with equal amount $(10 \mu \mathrm{g} /$ dish) of the expression plasmid for wild-type or mutant PPARG2s. Whole cell extracts were fractionated by SDS-PAGE and subjected to western blot with anti-PPARG2 antibody against the hinge region of PPARG2. The band in the lane of PPARG2-dNP495L that exhibits retarded mobility close to the position of wild-type PPARG2 (arrow) appears to be non-specific. (C) The DNEs of PPARG2-P495L and dNP495L on the troglitazone-dependent transactivation driven by the wild-type PPARG2s. CV1 cells were transfected with $15 \mathrm{ng}$ of wild-type or mutant PPARG2s together with $300 \mathrm{ng}$ of tk-AoxPPRE-Luc in the absence (open bars) or presence (solid bars) of $5 \mu \mathrm{M}$ troglitazone (lanes 1-11). Tro, troglitazone $(5 \mu \mathrm{M})$. The transactivation function of wild-type PPARG2 was inhibited by the co-expression of a twofold excessive amount (30 ng) of PPARG2-P495L or dNP495L (lanes 10 and 11). ${ }^{\star} P<0.05$. (D) 3T3-L1 cells were transfected with $15 \mathrm{ng}$ of wild-type PPARG2 and $300 \mathrm{ng}$ of tk-AoxPPRE-Luc in the absence (open bar) or presence (solid bars) of $5 \mu \mathrm{M}$ troglitazone. The transactivation function of wild-type PPARG2 was inhibited by the co-expression of a twofold excessive amount (30 ng) of PPARG2-P495L or dNP495L. ${ }^{*} P<0.05$.

PPARG2-mediated activity (Fig. 1C). A functional PPRE has been reported in the promoters of the human and mouse adipose differentiation-related protein $(A D R P)$ genes (Tachibana et al. 2005). We examined the DNE on the troglitazone-induced activity of the reporter gene, hADRP-4K-Luc, where the human ADRP promoter containing $-2981 /+1066$ was fused with luciferase gene. Ligand-induced activity of the ADRPderived PPRE by dNPPARG2 (lanes 4 and 5 ) was similar to that by wild-type PPARG2 (lanes 2 and 3), suggesting that deletion of NTD does not affect the transactivation function of the ADRP gene. While co-expression of twofold excessive amount of $\mathrm{P} 495 \mathrm{~L}$ did not repress the troglitazone-dependent transactivation induced by wild-type PPARG2, same amount of PPARG2-dNP495L exhibited mild but significant DNE (Fig. 2B), suggesting that NTD truncation potentiates DNE on ligand-induced transactivation via ADRP-derived PPRE.

\section{The DNE of mutant THRB1-K443E is not potentiated by the truncation of its NTD}

To compare the effect of the NTD truncation of PPARG2 with that of THRB1, we generated THRB1dNK443E (Fig. 3A), in which the NTD was deleted from a mutant THRB1-K443E that had been identified in a patient with RTH (Sasaki et al. 1995). The expression levels of THRB1-K443E and THRB1-dNK443E were 


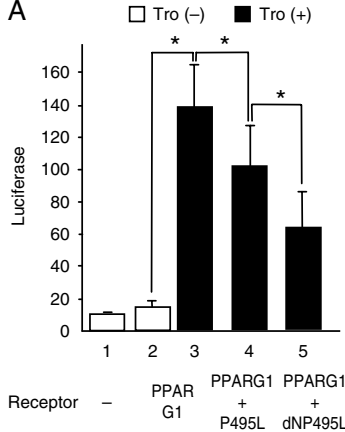

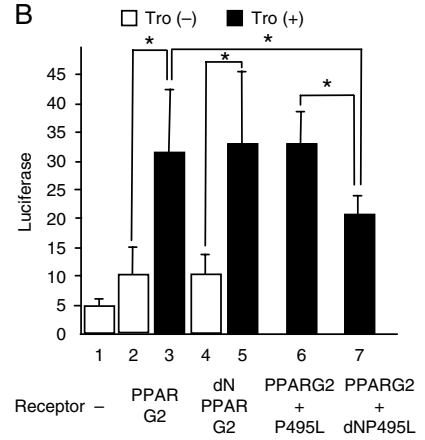

Figure 2 NTD truncation of PPARG2 enhances its DNE on the PPARG1-mediated activity of Aox-PPRE and the transactivation of the human ADRP promoter driven by PPARG2. (A) Truncation of NTD from PPARG2-P495L potentiates its DNE on the transactivation driven by liganded PPARG1. CV1 cells were transfected with $15 \mathrm{ng}$ of wild-type mouse PPARG1 together with $300 \mathrm{ng}$ of tk-AoxPPRE-Luc in the absence (open bars) or presence (solid bars) of $5 \mu \mathrm{M}$ troglitazone. Tro, troglitazone $(5 \mu \mathrm{M})$. The transactivation function of wild-type PPARG1 (lane 3) was inhibited by the co-expression of a twofold excessive amount (30 ng) of PPARG2-P495L or dNP495L (lanes 4 and 5). ${ }^{*} P<0.05$. (B) Twofold molar excess of PPARG2-dNP495L but not P495L exhibits DNE on the activity of the human ADRP promoter induced by liganded wild-type PPARG2. CV1 cells were transfected with $15 \mathrm{ng}$ of wild-type PPARG2 together with $300 \mathrm{ng}$ of hADRP-4KLuc in the absence (open bars) or presence (solid bars) of $5 \mu \mathrm{M}$ troglitazone. Tro, troglitazone $(5 \mu \mathrm{M})$. Ligand-induced activity of the ADRP-PPRE by dNPPARG2 was similar to that by wild-type PPARG2. The transactivation function of wild-type PPARG2 (lanes 2 and 3) was inhibited by the co-expression of a twofold excessive amount (30 ng) of PPARG2-dNP495L (lane 7) but not P495L (lane 6). * $P<0 \cdot 05$.

comparable with that of wild-type THRB1 (Fig. 3B). The luciferase-based reporter gene, which had a typical T3-responsive element (TRE) fused to the tk promoter (tk-TREpal-Luc), was transfected into CV1 cells together with the wild-type and mutant THRB1 expression plasmids. Unliganded THRB1 alone significantly repressed the basal transcriptional activity (Fig. 3C), suggesting transcriptional silencing. As we reported previously (Sasaki et al. 1995), the co-expression of THRB1-K443E reduced the T3dependent transactivation of tk-TREpal-Luc stimulated by wild-type THRB1, indicating that THRB1-K443E has a DNE on wild-type THRB1. Contrary to the results with PPARG2-P495L (Fig. 1C, lanes 3, 10, and 11), the DNE induced by THRB1-dNK443E was comparable with that of full-length THRB1-K443E, suggesting that NTD truncation does not affect the DNE.

\section{Truncation of the NTD in PPARG2s, but not THRB1-K443E, facilitates the in vitro interaction between its LBD and NCoR}

The enhancement of the DNE by the NTD truncation in PPARG2-P495L led us to investigate whether this domain modulates the interaction of its LBD with CoR. We performed an in vitro binding assay using bacterially expressed NCoR fused to GST (GST-NCoR) and ${ }^{35}$ S-radiolabeled receptors. Deletion of the NTD from PPARG2-P495L drastically increased its binding affinity to NCoR (Fig. 4A, lanes 8 and 9). We tested another mutant PPARG2, PPARG2-V318M. This mutant PPARG2 possesses an amino acid substitution corresponding to PPARG1-V290M (Barroso et al. 1999), LBD of which has the structure different from that of PPARG1-P467L (Kallenberger et al. 2003). Although PPARG2-V318M may have some affinity for PPARG ligands (Agostini et al. 2004), in vitro experiments allowed us to evaluate the NCoR interaction in the ligand-free condition. As shown in Fig. 4B, the NTDdeleted mutant, PPARG2-dNV318M, also exhibited increased affinity for NCoR (lanes 5 and 6). The in vitro translated products of THRB1 and THRB1$\mathrm{K} 443 \mathrm{E}$ produced two major bands due to the two initiation methionines in their NTDs (Fig. 4C, lanes 1 and 2), while THRB1-dNK443E appeared as a single band (lane 3). Although we utilized an excessive amount of GST-NCoR and adjusted the amounts of

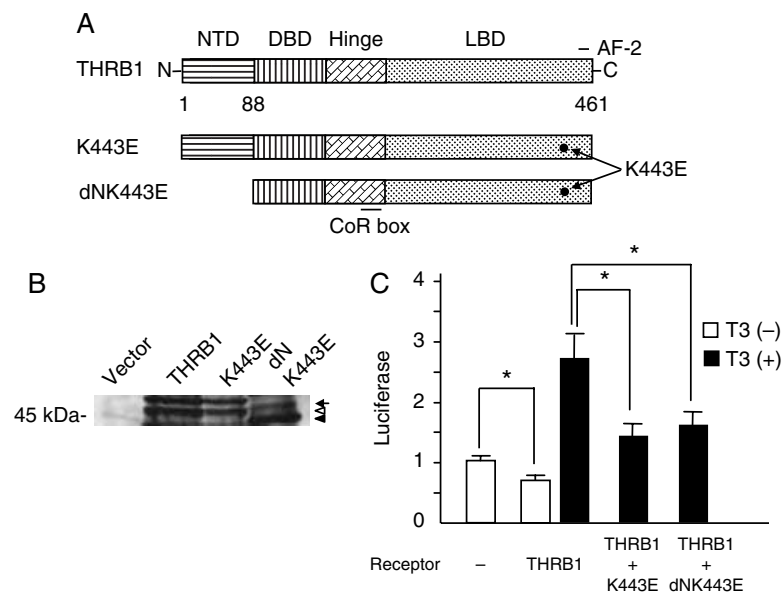

Figure 3 The effect of NTD truncation on the DNE of THRB1K443E. (A) A schematic representation of wild-type THRB1, THRB1-K443E, and dNK443E. K443E, THRB1-K443E; dNK443E, THRB1-dNK443E. The arrows indicate the substitution of lysine at codon 443 with glutamine in THRB1-K443E and dNK443E. The numbers below the schema represent the position in the amino acid sequence. The NTD encompassing initiation methionine and cysteine at codon 88 was truncated in THRB1dNK443E. (B) The expression levels of THRB1-K443E (arrow) and dNK443E (solid arrowhead) were comparable with that of wild-type THRB1 (arrows) CV1 cells in $10 \mathrm{~cm}$ dish were transfected with the equal amount (10 $\mu \mathrm{g} /$ dish) of expression plasmids for wild-type or mutant THRB1s. Whole cell extracts were fractionated by SDS-PAGE and subjected to western blot with anti-THRB1 antibody against the LBD of THRB1. The band in the lane of wild-type THRB1 and THRB1-K443E that exhibits faster mobility (open arrowhead) appears to be the translation variant from downstream methionine. $(C)$ In the presence (solid bars) and absence (open bars) of $100 \mathrm{nM} \mathrm{T3}$, wild-type THRB1 (15 ng) and tk-TREpal-Luc (300 ng/dish) were co-transfected into CV1 cells along with a twofold excessive amount ( $30 \mathrm{ng} /$ dish) of THRB1-K443E or dNK443E. * $P<0 \cdot 05$. 


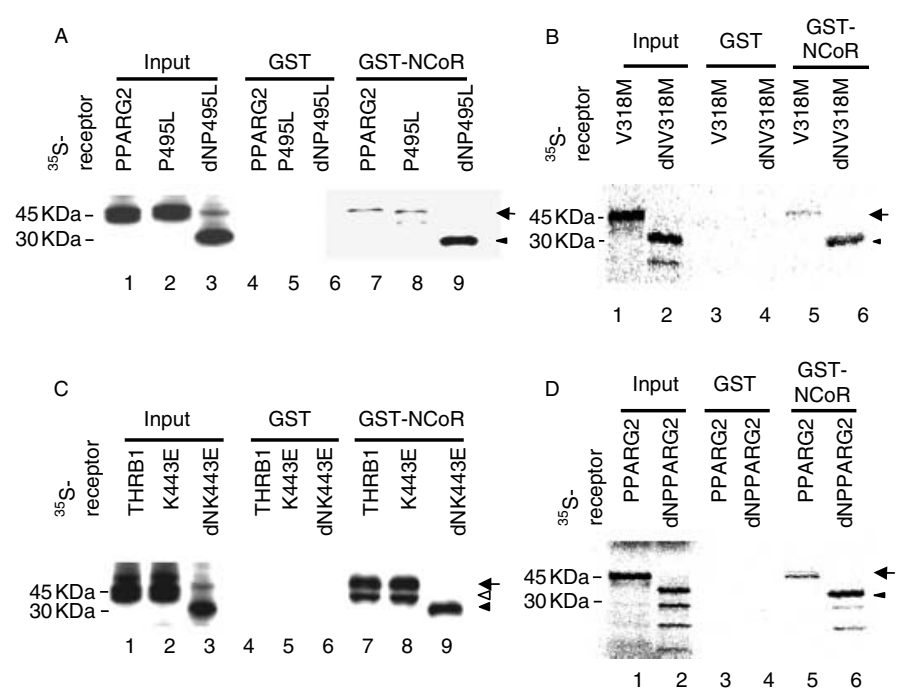

Figure 4 The effect of PPARG2-NTD truncation on the interaction between LBD and NCoR in vitro. (A) The wild-type PPARG2 (arrow), PPARG2-P495L (arrow), and PPARG2-dNP495L (solid arrowhead) were labeled with ${ }^{35} \mathrm{~S}$-methionine and incubated with GST protein that was fused to the receptor interacting domain of NCoR (GST-NCoR; lanes 7-9). P495L, PPARG2-P495L; dNP495L, PPARG2-dNP495L. The binding fraction was analyzed by SDS-PAGE. (B) PPARG2-V318M (arrow) and PPARG2-dNV318M (solid arrowhead) were labeled with ${ }^{35}$ S-methionine and incubated with GST protein that was fused to the receptor interacting domain of NCoR (GST-NCoR; lanes 5 and 6). V318M, PPARG2-V318M; dNV318M, PPARG2-dNV318M. The binding fraction was analyzed by SDS-PAGE. (C) ${ }^{35}$ S-labeled wild-type THRB1, K443E, and dNK443E were incubated with GST-NCoR (lanes 7-9). The affinities of wild-type THRB1 (arrows), THRB1-K443E (arrows), and dNK443E (solid arrowhead) for GST-NCoR were comparable. The band in the lane of THRB1-K443E that exhibits faster mobility (open arrowhead) appears to be the translation variant from downstream methionine. K443E, THRB1-K443E; dNK443E, THRB1-dNK443E. (D) The wild-type PPARG2 (arrow) and dNPPARG2 (arrowhead) were labeled with ${ }^{35} \mathrm{~S}$-methionine and incubated with GST-NCOR. The binding fraction was analyzed by SDS-PAGE.

radiolabeled receptors in the input lanes (lanes 1-3), the signals from discrete bands were not affected by truncation of the NTD (lanes 8 and 9). Because there is the possibility that structure of CoR-binding surface may be altered in mutant PPARG2s, we tested the wildtype PPARG2 and dNPPARG2. As shown in Fig. 4D (lanes 5 and 6 ), the interaction of wild-type PPARG2 with NCoR was again enhanced by the truncation of its NTD. Together, it is considered that the NTD in PPARG2s, but not THRB1-K443E, is able to prevent the interaction of NCoR with its LBD.

\section{The construction of the chimeric receptor, PT, in which PPARG2-derived NTD and DBDs were fused to a THRB1-derived LBD}

To exclude the influence of endogenous ligand in CV1 and 3T3L1 cells, we further attempted to generate a chimeric receptor, in which the PPARG2-LBD was replaced with a THRB1-derived LBD. The PPAR-RXR heterodimer binds to a DR1-type PPRE with PPAR on the $5^{\prime}$ end and RXR on the $3^{\prime}$ end (Desvergne \& Wahli 1999). The inverted polarity is dictated by the A- and T-boxes in the PPARG2-DBD. Based on these considerations, we constructed a chimeric receptor designated PT, which possesses A- and T-boxes derived from PPARG2 (Fig. 5A). A gel shift assay revealed that the PT chimera, as well as PPARG2, formed heterodimers with RXR on PPRE (Fig. 5B). As expected, deletion of the A- or T-box abolished heterodimer formation with RXR (data not shown). As shown in Fig. 4C, the PT chimera activated tk-AoxPPRE-Luc in the presence of $100 \mathrm{nM}$ T3 to a level similar to that induced by wild-type PPARG2 in the presence of $5 \mu \mathrm{M}$ troglitazone. In contrast with wild-type PPARG2, the PT chimera significantly repressed basal transcriptional activity (Fig. 5C, inset), suggesting that PT possesses a silencing function in the absence of T3. The PT chimera did not stimulate tk-TREpal-Luc, presumably due to the specificity of the PPARG2-derived DBD (Fig. 5D). 


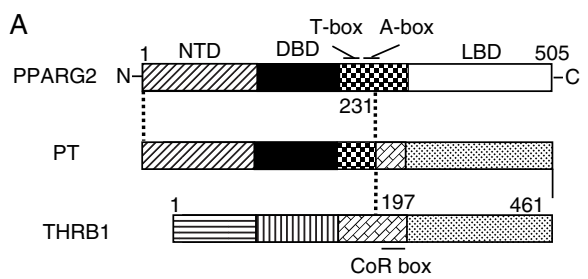

B
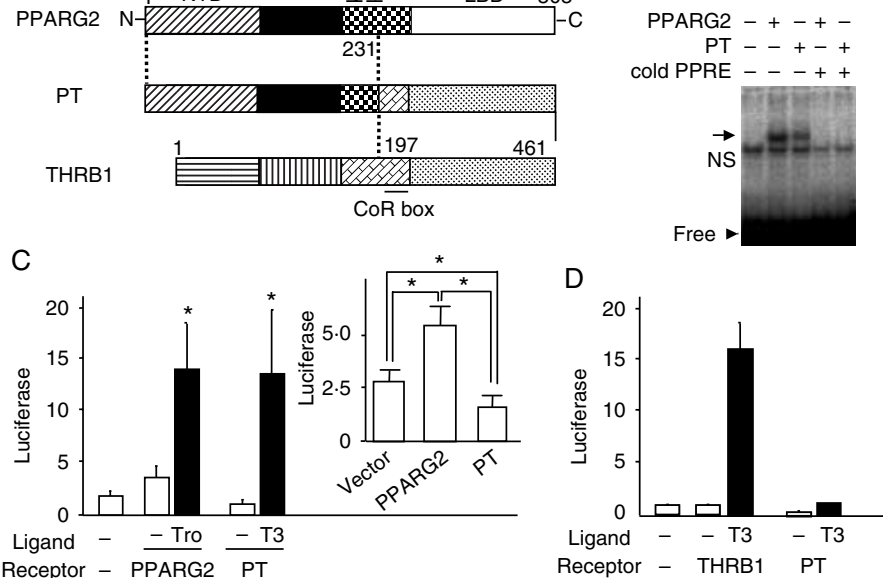

Figure 5 Construction and functional evaluation of $\mathrm{PT}$ chimera.

(A) A schematic representation of PT chimera. The N-terminal half (codon 1-231) of wild-type PPARG2, which contains NTD, DBD, and the A- and T-boxes, was fused to the C-terminal half of wild-type THRB1, which harbors the CoR box and LBD (codon 197-461). PPARG2, wild-type PPARG2; THRB1, wild-type THRB1. (B) The affinity of the PT-RXR heterodimer for Aox-PPRE is similar to that of wild-type PPARG2. ${ }^{32}$ P-labeled PPRE derived from the Aox promoter was incubated with in vitro translated PT or wild-type PPARG2. In all lanes, in vitro translated mouse RXRB was added. The arrow and NS indicate the specific and the non-specific binding respectively. (C) T3-dependent transactivation by the PT is comparable to that by wild-type PPARG2 in the presence of troglitazone. The luciferase activity of tk-AoxPPRE-Luc was co-transfected with wild-type PPARG2 or PT in the presence of $5 \mu \mathrm{M}$ troglitazone or $100 \mathrm{nM}$ T3 respectively. In the absence of T3, PT repressed the basal reporter activity (silencing), while wild-type PPARG2 enhanced it (inset). (D) The PT is not able to stimulate the TRE. TREpaltk-Luc was co-transfected with wild-type THRB1 or the PT in the presence (solid bars) or absence (open bars) of $100 \mathrm{nM} \mathrm{T3.}{ }^{*} P<0 \cdot 05$.

\section{The truncation of NTD potentiates the DNE of the PT chimera receptor via interaction with NCoR}

We tested whether the PT chimera in the absence of T3 also interferes with the troglitazone-induced transactivation driven by wild-type PPARG2. In CV1 cells, transactivation of tk-AoxPPRE-Luc driven by liganded wild-type PPARG2 was inhibited by the co-expression of the PT chimera in the absence of T3 (Fig. 6B, lanes 3 and 4). The CoR box in the THRB1 hinge region (Horlein et al. 1995) is necessary for interaction with CoRs (Marimuthu et al. 2002). To investigate whether the DNE of the PT chimera is mediated through its association with CoRs, we introduced the AHT mutation (Horlein et al. 1995) into the CoR box of the PT chimera (Fig. 6A). As illustrated in Fig. 6B (lanes 4 and 6 ), the DNE of PT-AHT was abrogated, indicating that the repression by the PT chimera was mediated through its interaction with CoRs. Subsequently, we constructed dNPT, in which the NTD was deleted from the PT chimera (Fig. 6A). While the T3-dependent transactivation by dNPT was similar to that of the PT chimera (Fig. 6C), the DNE of dNPT was more potent than that of the full-length PT chimera (Fig. 6B, lanes 4 and 5). The introduction of the AHT mutation into the CoR box of dNPT again reduced its DNE (Fig. 6B, lanes 5 and 7). The expression levels of dNPT, PT-AHT, and dNPT-AHT were comparable with that of the PT chimera (Fig. 6D). Similar results were obtained in 3T3L1 pre-adipocytes (Fig. 6E). As shown in Fig. 6F, the in vitro interaction with $\mathrm{NCoR}$ was enhanced by the truncation of the NTD in the PT chimera. These results indicate that PPARG2-NTD inhibits the binding of CoRs with the LBD derived from PPARG2 as well as that derived from THRB1, resulting in transcriptional upregulation.

\section{Discussion}

It was reported that the association of CoRs requires the CoR box, which is typically found in the hinge region of THRs and RARA (Horlein et al. 1995). However, later analyses revealed that the amino acid residues directly 
A

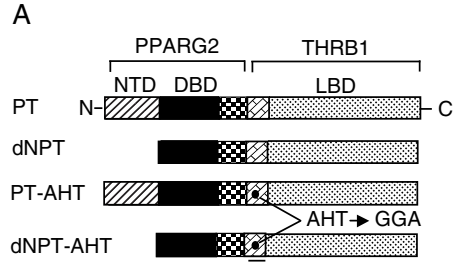

CoR box

C

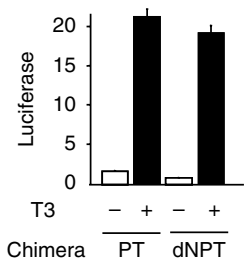

D

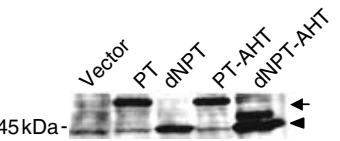

$\mathrm{E}$
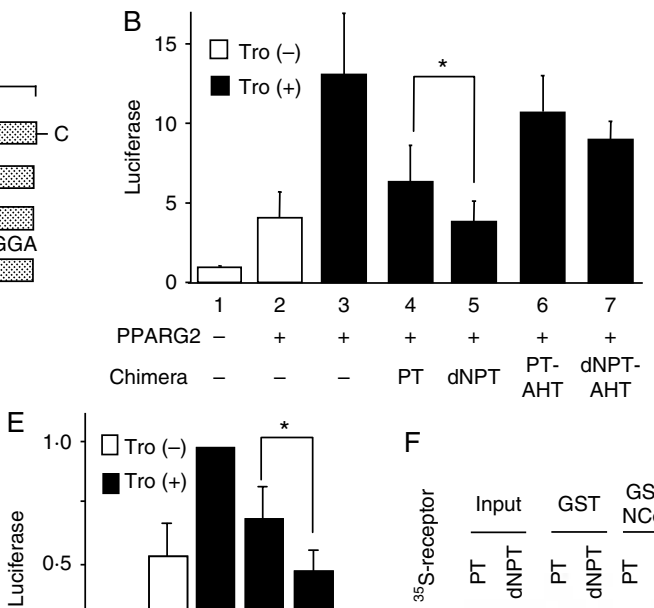

Figure 6 The DNE of the PT and its truncation mutant, dNPT. (A) A schematic representation of the PT chimera, dNPT, PT-AHT, and dNPT-AHT. The NTD encompassing the initiation methionine and histidine at codon 127 derived from wild-type PPARG2 was truncated in dNPT and dNPT-AHT. The arrows indicate the position of the $\mathrm{AHT}$ residues at codon 223,224 , and 227 that were mutated to GGA in the CoR box derived from THRB1. (B) CV1 cells were transfected with $15 \mathrm{ng}$ of the wild-type PPARG2s together with $300 \mathrm{ng}$ of tk-AoxPPRE-Luc in the absence (open bars) or presence (solid bars) of $5 \mu \mathrm{M}$ troglitazone (lanes 1-3). The transactivation function of wild-type PPARG2 ( $15 \mathrm{ng}$ ) was inhibited by the co-expression of a twofold molar excessive amount ( $30 \mathrm{ng}$ ) of the PT chimera or dNPT (lanes 4 and 5 respectively). PPARG2, wild-type PPARG2. (C) In the presence (solid bars) or absence (open bars) of T3, $300 \mathrm{ng}$ of tk-AoxPPRE-Luc was co-transfected into CV1 cells along with $15 \mathrm{ng}$ of the PT chimera or dNPT. The T3-dependent transactivation of tk-AoxPPRE-Luc by the PT chimera is comparable with that of dNPT. (D) The expression levels of dNPT (arrowhead), PT-AHT (arrow), and dNPT-AHT (arrowhead) were comparable with that of the PT chimera (arrow). CV1 cells in $10 \mathrm{~cm}$ dish were transfected with the equal amount of expression plasmids ( $10 \mu \mathrm{g} / \mathrm{dish})$ for wild-type or mutant THRB1s. Whole cell extracts were fractionated by SDS-PAGE and subjected to western blot with anti-THRB1 antibody against the hinge region of PPARG2. (E) 3T3-L1 cells were transfected with $15 \mathrm{ng}$ of wild-type PPARG2 and $300 \mathrm{ng}$ of tk-AoxPPRE-Luc in the absence (open bars) or presence (solid bars) of $5 \mu \mathrm{M}$ troglitazone. The transactivation function of wild-type PPARG2 was inhibited by the co-expression of a twofold excessive amount ( $30 \mathrm{ng}$ ) of PT chimera or dNPT. ${ }^{*} P<0 \cdot 05$. (F) The PT (arrow) and dNPT (arrowhead) were labeled with ${ }^{35} \mathrm{~S}$-methionine and incubated with GST-NCoR. The binding fraction was analyzed by SDS-PAGE and visualized by autoradiography.

interacting with CoRs are distributed widely in THRLBD, although the CoR box is necessary for maintaining the global structure of the THR-LBD for CoR interaction (Marimuthu et al. 2002). This implies that the CoR box is not necessarily the determinant of CoR interaction. X-ray crystal analysis showed that CoRs interact with the PPARA-LBD (Xu et al. 2002, Agostini et al. 2004), the interaction surface of which is very similar to that of the THR-LBD (Kallenberger et al. 2003). PPARA has high homology $(\sim 71 \%)$ in the amino acid sequence of its LBD with the PPARG-LBD (Xu et al. 2002, Agostini et al. 2004). Direct binding of CoRs with wild-type PPARG2 was demonstrated by GST pulldown assay (Zamir et al. 1997, Krogsdam et al. 2002,
Stanley et al. 2003), co-immunoprecipitation (Gurnell et al. 2000, Yu et al. 2005), gel shift assay (Lee et al. 2002), and an in vitro pulldown assay with RXR-PPARG2 heterodimers on PPREs (Krogsdam et al. 2002). Using a ChIP assay, Guan et al. (2005) showed that, in adipocytes without the addition of an exogenous ligand, PPARG2 molecules associated with CoRs are present in PPREs in the promoter region of the glycerol kinase gene (Guan et al. 2005). Similar results were reported in other PPARG-target genes including oxidized low-density lipoprotein receptor 1 (Chui et al. 2005), aP2, and PPARG (Picard et al. 2004). These findings suggest that unliganded PPARG2 recruits CoRs, resulting in transcriptional silencing. 
It should be noted, however, that the NCoR recruitment may depend on the sequence of PPREs (Guan et al. 2005). This could explain why twofold excessive amount of PPARG2-P495L failed to exhibit DNE on the ADRP promoter activity (Fig. 2B).

PPARG-LBD possesses a very large ligand-binding pocket (1300 A ${ }^{3}$; Desvergne \& Wahli 1999) and can accommodate a variety of ligands (Michalik et al. 2006, Semple et al. 2006). It is currently difficult to completely eliminate the endogenous ligands produced by cells (DiRenzo et al. 1997, Werman et al. 1997, Kim et al. 1998, Camp et al. 2001, Madsen et al. 2003, Tzameli et al. 2004, Yano et al. 2007). The existence of endogenous ligands may mask the silencing by unliganded PPARG2. This could explain why conventional reporter assays have failed to detect the silencing effect by PPARG2 despite the absence of exogenous ligands (Zamir et al. 1997, Barroso et al. 1999, Zhang et al. 1999, Chatterjee 2001, Gurnell et al. 2003, Agostini et al. 2004, Semple et al. 2006). For the creation of ligand-free conditions in vivo, we took advantage of the fact that PPARG1-P467L is resistant to various ligands (Barroso et al. 1999, Agostini et al. 2004) and generated a corresponding mutant, PPARG2-P495L. Our analyses with a conventional luciferase reporter assay demonstrated that NTD truncation potentiated the DNE of PPARG2-P495L on the ligand-induced transactivation induced by wild-type PPARG2 (Fig. 1C and D). Potentiation of DNE by NTD truncation was also observed in the PPARG1-mediated activation of Aox-PPRE (Fig. 2A) and in the transactivation of the human ADRP promoter stimulated by PPARG2 (Fig. 2B). Moreover, in the cell-free conditions with GST pulldown assay, truncation of NTD enhances NCoR binding with not only PPARG2-P495L (Fig. 4A) and V318M (Fig. 4B) but also wild-type PPARG2 (Fig. 4D). These results indicate that the NTD controls the association of CoR with unliganded PPARG2-LBD via inter-domain communication, which was originally proposed in the context of ligand-dependent transactivation by PPARG2 (Shao et al. 1998). It is necessary in future to examine whether NTD modulates the effect of ligand to dissociate NCoR from LBD.

We created a chimera, PT, by replacing PPARG-LBD with THRB-LBD. This chimeric receptor has many advantages for analyzing the function of unliganded PPARG2. First, the ligand-binding pocket of THRBLBD $\left(600 \mathrm{~A}^{3}\right)$ is much smaller than that of PPARGs (Desvergne \& Wahli 1999) and is specific for T3. The concentration of T3 in culture medium is easy to measure, and the method for its removal is established (Samuels et al. 1979). Second, the interaction of THRBLBD with CoR has been characterized in detail (Horlein et al. 1995, Yang et al. 1999, Marimuthu et al. 2002). Accumulated information from the natural THRB1 mutants in RTH is also available (Refetoff et al. 1993). The functional relevance in the context of
DNEs is confirmed in mutant PPARGs harboring artificial amino acid substitutions corresponding to those of mutant THRB1s in vitro (Zamir et al. 1997, Gurnell et al. 2000, Chatterjee 2001, Nugent et al. 2001, Park et al. 2003) and in vivo (Freedman et al. 2005). Finally, THR-LBD is flexible with regard to the orientation of its DBD in a variety of TREs (Kurokawa et al. 1993). This feature is critical for mimicking the inverted polarity of the PPARG2-RXR heterodimer in the PPRE (Desvergne \& Wahli 1999). Using the PT chimera, we observed that NTD truncation enhanced the DNE on the ligand-dependent transactivation induced by wild-type PPARG2. This suggests that the PPARG2-NTD functions to regulate the association of CoR with unliganded LBD. The data from the AHT mutation in CoR box (Horlein et al. 1995) of the PT chimera indicate that DNEs are mediated through CoR recruitment but not the RXR squelching proposed previously (Juge-Aubry et al. 1995, Hunter et al. 1996, Winrow et al. 1996, Lu \& Cheng 2010).

PPARG2-NTD may have multiple functions including direct interactions with p300 (Gelman et al. 1999) and Tip60 (van Beekum et al. 2008) and modification by small ubiquitin-related modifier-1 (Ohshima et al. 2004, Yamashita et al. 2004). Consistently, a microarray analysis using a chimera between PPARG2 and PPAR $\delta$ (PPARD) revealed that the PPARG2-NTD is the major determinant for the PPARG2-specific gene expression profile (Hummasti \& Tontonoz 2006). However, Bugge et al. (2009) recently reported that, of the 257 genes induced by rosiglitazone, only 25 genes exhibited the reduced transcriptional activity in the cell expressing truncated PPARG2 lacking NTD. We speculate that the NTD-dependent function of unliganded PPARG2 to regulate the CoR association may be another determinant for the PPARG2-specific gene expression profile. An attempt to confirm the in vivo function of NTD in unliganded PPARG2 is currently underway in our laboratory. Our study indicates that the inter-domain communication between NTDs and LBDs, originally proposed in the context of ligand-dependent transactivation (Shao et al. 1998), also plays a role in CoR association and the silencing function mediated by unliganded PPARG2. Similar modification of LBD-CoR interactions by the NTD has been suggested in other NHRs (Kumar \& Thompson 2003, Pippal \& Fuller 2008). For example, insulin-induced phosphorylation in the PPARA-NTD enhances the dissociation of CoRs from its LBD (Juge-Aubry et al. 1999). Direct interaction between NTDs and LBDs was reported in estrogen receptor (Metivier et al. 2000, Metivier et al. 2001) and androgen receptor (AR; Cheng et al. 2002, He \& Wilson 2002, Liao et al. 2003). In AR, the interaction between NTD and LBD, referred to as 'N/C interaction' (He \& Wilson 2002), was interfered by the overexpression of NCoR or SMRT (Liao et al. 2003). It is also necessary 
to confirm the inter-domain communication of unliganded PPARG2 using the chromatinized PPREs.

Hollenberg et al. (1996) reported that pituitaryspecific THRB2 does not have a silencing function in the absence of T3. One may assume common features between the THRB2-NTD and PPARG2-NTD in the mechanism of loss of silencing function. However, in contrast to PPARG2 (Fig. 4D), the truncation of the NTD from THRB2 did not affect its physical interaction with CoRs in vitro (Yang et al. 1999). Thus, the mechanism underlying the CoR interaction of THRB2 is different. According to Yang et al. (1999), CoRs interact with not only THRB2-LBD but also its NTD, and CoR-NTD contact neutralizes the repressive function of CoRs. On the other hand, the same authors reported that, in wild-type THRB1, NTD truncation did not affect its silencing function or in vitro binding with CoR (Yang et al. 1999). This is in agreement with our finding that deletion of the NTD from THRB1-K443E did not affect its interaction with NCoR (Fig. 4C) or its DNE on the transactivation induced by T3-bound THRB1 (Fig. 3C).

Given that the transcriptional silencing by unliganded PPARG2 is controlled by its NTD, genetic modification of this domain may alter its insulin sensitivity in vivo. In the PPARG2-NTD, the serine residue at codon 112 is phosphorylated by MAPK (Hu et al. 1996, Adams et al. 1997, Camp \& Tafuri 1997). Rangwala et al. (2003) generated knock-in mice, in which the serine at codon 112 was substituted for phosphorylation-resistant alanine (S112A), and noted an increase in insulin sensitivity. Of note, thiazolidinedione-sensitive genes such as phosphoenolpyruvate carboxykinase (PEPCK) were not significantly activated in S112A mice. Rangwala et al. (2003) suggested that the property of S112A-PPARG2 in the reduction of insulin resistance may be qualitatively different from that of liganded PPARG2. In agreement with this, Armoni et al. (2003) demonstrated in vitro that S112A substitution diminishes the silencing activity caused by unliganded PPARG2. Polymorphism in the NTD of the PPARG2 gene from CCA (proline) at codon 12 to GCA (alanine) (P12A) is also associated with higher insulin sensitivity (Deeb et al. 1998). However, it was shown that transactivation by PPARG2-P12A in the presence of a cognate ligand is similar or reduced compared to that of the wild-type receptor (Deeb et al. 1998, Masugi et al. 2000). Further studies are required to clarify whether these genetic modifications in the NTD may affect the insulin sensitivity through the modulation of the interaction between CoRs and unliganded PPARG2.

\section{Declaration of interest}

The authors declare that there is no conflict of interest that could be perceived as prejudicing the impartiality of the research reported.

\section{Funding}

This work was supported, in part, by a Health Sciences Research Grant to H Nakamura and a Grant-in Aid for Scientific Research to H Morita, S Sasaki, and H Nakamura from the Ministry of Education, Culture, Sports, Science, and Technology in Japan (grant number 13671181).

\section{Acknowledgements}

We are grateful to the following researchers for providing the plasmids: Ronald M Evans (Howard Hughes Medical Institute, The Salk Institute for Biological Studies, USA) for pCMX-hTHRB1 and tk-TREp-Luc; Akira Kakizuka (Kyoto University, Japan) for pCH111; Toshiya Tanaka (University of Tokyo, Japan) for hADRP-4k-Luc; and Steven A Kliewer (Glaxo Wellcome Research and Development) for pSG5-PPARG2 and tk-AoxPPRE-Luc.

\section{References}

Adams M, Reginato MJ, Shao D, Lazar MA \& Chatterjee VK 1997 Transcriptional activation by peroxisome proliferator-activated receptor gamma is inhibited by phosphorylation at a consensus mitogen-activated protein kinase site. Journal of Biological Chemistry 272 5128-5132. (doi:10.1074/jbc.272.43.27295)

Agostini M, Gurnell M, Savage DB, Wood EM, Smith AG, Rajanayagam O, Garnes KT, Levinson SH, Xu HE, Schwabe JW et al. 2004 Tyrosine agonists reverse the molecular defects associated with dominant-negative mutations in human peroxisome proliferator-activated receptor gamma. Endocrinology 145 1527-1538. (doi:10.1210/en.2003-1271)

Armoni M, Kritz N, Harel C, Bar-Yoseph F, Chen H, Quon MJ \& Karnieli E 2003 Peroxisome proliferator-activated receptorgamma represses GLUT4 promoter activity in primary adipocytes, and rosiglitazone alleviates this effect. Journal of Biological Chemistry 278 30614-30623. (doi:10.1074/jbc.M304654200)

Barroso I, Gurnell M, Crowley VE, Agostini M, Schwabe JW, Soos MA, Maslen GL, Williams TD, Lewis H, Schafer AJ et al. 1999 Dominant negative mutations in human PPARgamma associated with severe insulin resistance, diabetes mellitus and hypertension. Nature 402 880-883. (doi:10.1038/47254)

van Beekum O, Brenkman AB, Grøntved L, Hamers N, van den Broek NJ, Berger R, Mandrup S \& Kalkhoven E 2008 The adipogenic acetyltransferase Tip60 targets activation function 1 of peroxisome proliferator-activated receptor gamma. Endocrinology 149 1840-1849. (doi:10.1210/en.2007-0977)

Bugge A, Grøntved L, Aagaard MM, Borup R \& Mandrup S 2009 The PPARgamma2 A/B-domain plays a gene-specific role in transactivation and cofactor recruitment. Molecular Endocrinology 23 794-808. (doi:10.1210/me.2008-0236)

Camp HS \& Tafuri SR 1997 Regulation of peroxisome proliferatoractivated receptor gamma activity by mitogen-activated protein kinase. Journal of Biological Chemistry 272 10811-10816. (doi:10. 1074/jbc.272.16.10811)

Camp HS, Chaudhry A \& Leff T 2001 A novel potent antagonist of peroxisome proliferator-activated receptor gamma blocks adipocyte differentiation but does not revert the phenotype of terminally differentiated adipocytes. Endocrinology 142 3207-3213. (doi:10.1210/en.142.7.3207)

Chatterjee VK 2001 Resistance to thyroid hormone, and peroxisomeproliferator-activated receptor gamma resistance. Biochemical Society Transactions 29 227-231. (doi:10.1042/BST0290227)

Cheng S, Brzostek S, Lee SR, Hollenberg AN \& Balk SP 2002 Inhibition of the dihydrotestosterone-activated androgen receptor by nuclear receptor corepressor. Molecular Endocrinology 16 1492-1501. (doi:10.1210/me.16.7.1492) 
Chui PC, Guan HP, Lehrke M \& Lazar MA 2005 PPARgamma regulates adipocyte cholesterol metabolism via oxidized LDL receptor 1. Journal of Clinical Investigation 115 2244-2256. (doi:10.1172/JCI24130)

Deeb SS, Fajas L, Nemoto M, Pihlajamaki J, Mykkanen L, Kuusisto J, Laakso M, Fujimoto W \& Auwerx J 1998 A Pro12Ala substitution in PPARgamma2 associated with decreased receptor activity, lower body mass index and improved insulin sensitivity. Nature Genetics 20 284-287. (doi:10.1038/3099)

Desvergne B \& Wahli W 1999 Peroxisome proliferator-activated receptors: nuclear control of metabolism. Endocrine Reviews $\mathbf{2 0}$ 649-688. (doi:10.1210/er.20.5.649)

DiRenzo J, Soderstrom M, Kurokawa R, Ogliastro MH, Ricote M, Ingrey S, Horlein A, Rosenfeld MG \& Glass CK 1997 Peroxisome proliferator-activated receptors and retinoic acid receptors differentially control the interactions of retinoid $\mathrm{X}$ receptor heterodimers with ligands, coactivators, and corepressors. Molecular and Cellular Biology 17 2166-2176.

Freedman B, Lee E, Park Y \& Jameson J 2005 A dominant negative peroxisome proliferator-activated receptor-gamma knock-in mouse exhibits features of the metabolic syndrome. Journal of Biological Chemistry 280 17118-17125. (doi:10.1074/jbc.M407539200)

Ge K, Guermah M, Yuan CX, Ito M, Wallberg AE, Spiegelman BM \& Roeder RG 2002 Transcription coactivator TRAP220 is required for PPAR gamma 2-stimulated adipogenesis. Nature 417 563-567. (doi:10.1038/417563a)

Gelman L, Zhou G, Fajas L, Raspe E, Fruchart JC \& Auwerx J 1999 p300 interacts with the $\mathrm{N}$ - and C-terminal part of PPARgamma2 in a ligand-independent and -dependent manner, respectively. Journal of Biological Chemistry 274 7681-7688. (doi:10.1074/jbc. 274.12.7681)

Guan HP, Ishizuka T, Chui PC, Lehrke M \& Lazar MA 2005 Corepressors selectively control the transcriptional activity of PPARgamma in adipocytes. Genes and Development 19 453-461. (doi:10.1101/gad.1263305)

Gurnell M, Wentworth JM, Agostini M, Adams M, Collingwood TN, Provenzano C, Browne PO, Rajanayagam O, Burris TP, Schwabe JW et al. 2000 A dominant-negative peroxisome proliferatoractivated receptor gamma (PPARgamma) mutant is a constitutive repressor and inhibits PPARgamma-mediated adipogenesis. Journal of Biological Chemistry 275 5754-5759. (doi:10.1074/jbc. 275.8.5754)

Gurnell M, Savage DB, Chatterjee VK \& O'Rahilly S 2003 The metabolic syndrome: peroxisome proliferator-activated receptor gamma and its therapeutic modulation. Journal of Clinical Endocrinology and Metabolism 88 2412-2421. (doi:10. 1210/jc.2003-030435)

He B \& Wilson EM 2002 The NH(2)-terminal and carboxylterminal interaction in the human androgen receptor. Molecular Genetics and Metabolism 75 293-298. (doi:10.1016/S10967192(02)00009-4)

Hollenberg AN, Monden T, Madura JP, Lee K \& Wondisford FE 1996 Function of nuclear co-repressor protein on thyroid hormone response elements is regulated by the receptor $\mathrm{A} / \mathrm{B}$ domain. Journal of Biological Chemistry 271 28516-28520. (doi:10. 1074/jbc.271.45.28516)

Horlein AJ, Naar AM, Heinzel T, Torchia J, Gloss B, Kurokawa R, Ryan A, Kamei Y, Soderstrom M, Glass CK et al. 1995 Ligand-independent repression by the thyroid hormone receptor mediated by a nuclear receptor co-repressor. Nature 377 397-404. (doi:10.1038/377397a0)

Hu E, Kim JB, Sarraf P \& Spiegelman BM 1996 Inhibition of adipogenesis through MAP kinase-mediated phosphorylation of PPARgamma. Science 274 2100-2103. (doi:10.1126/science. 274.5295.2100)

Hummasti S \& Tontonoz P 2006 The peroxisome proliferatoractivated receptor N-terminal domain controls isotype-selective gene expression and adipogenesis. Molecular Endocrinology 20 1261-1275. (doi:10.1210/me.2006-0025)
Hunter J, Kassam A, Winrow CJ, Rachubinski RA \& Capone JP 1996 Crosstalk between the thyroid hormone and peroxisome proliferator-activated receptors in regulating peroxisome proliferator-responsive genes. Molecular and Cellular Endocrinology 116 213-221. (doi:10.1016/0303-7207(95)03717-9)

Juge-Aubry CE, Gorla-Bajszczak A, Pernin A, Lemberger T, Wahli W, Burger AG \& Meier CA 1995 Peroxisome proliferatoractivated receptor mediates cross-talk with thyroid hormone receptor by competition for retinoid X receptor. Possible role of a leucine zipper-like heptad repeat. Journal of Biological Chemistry 270 18117-18122. (doi:10.1074/jbc.270.30.18117)

Juge-Aubry CE, Hammar E, Siegrist-Kaiser C, Pernin A, Takeshita A, Chin WW, Burger AG \& Meier CA 1999 Regulation of the transcriptional activity of the peroxisome proliferator-activated receptor alpha by phosphorylation of a ligand-independent trans-activating domain. Journal of Biological Chemistry 274 10505-10510. (doi:10.1074/jbc.274.15.10505)

Kallenberger BC, Love JD, Chatterjee VK \& Schwabe JW 2003 A dynamic mechanism of nuclear receptor activation and its perturbation in a human disease. Nature Structural Biology 10 136-140. (doi:10.1038/nsb892)

Kawai K, Sasaki S, Morita H, Ito T, Suzuki S, Misawa H \& Nakamura H 2004 Unliganded thyroid hormone receptor betal represses liver $\mathrm{X}$ receptor alpha/oxysterol-dependent transactivation. Endocrinology 145 5515-5524. (doi:10.1210/en.2004-0382)

Kim JB, Wright HM, Wright M \& Spiegelman BM 1998 ADD1/SREBP1 activates PPARgamma through the production of endogenous ligand. PNAS 95 4333-4337. (doi:10.1073/pnas.95.8.4333)

Krogsdam AM, Nielsen CA, Neve S, Holst D, Helledie T, Thomsen B, Bendixen C, Mandrup S \& Kristiansen K 2002 Nuclear receptor corepressor-dependent repression of peroxisome-proliferatoractivated receptor delta-mediated transactivation. Biochemical Journal 363 157-165. (doi:10.1042/0264-6021:3630157)

Kumar R \& Thompson EB 2003 Transactivation functions of the N-terminal domains of nuclear hormone receptors: protein folding and coactivator interactions. Molecular Endocrinology 17 1-10. (doi:10.1210/me.2002-0258)

Kurokawa R, Yu VC, Naar A, Kyakumoto S, Han Z, Silverman S, Rosenfeld MG \& Glass CK 1993 Differential orientations of the DNA-binding domain and carboxy-terminal dimerization interface regulate binding site selection by nuclear receptor heterodimers. Genes and Development 7 1423-1435. (doi:10. 1101/gad.7.7b.1423)

Lee G, Elwood F, McNally J, Weiszmann J, Lindstrom M, Amaral K, Nakamura M, Miao S, Cao P, Learned RM et al. 2002 T0070907, a selective ligand for peroxisome proliferator-activated receptor gamma, functions as an antagonist of biochemical and cellular activities. Journal of Biological Chemistry 277 19649-19657. (doi:10.1074/jbc.M200743200)

Liao G, Chen LY, Zhang A, Godavarthy A, Xia F, Ghosh JC, Li H \& Chen JD 2003 Regulation of androgen receptor activity by the nuclear receptor corepressor SMRT. Journal of Biological Chemistry 278 5052-5061. (doi:10.1074/jbc.M206374200)

Lu C \& Cheng SY 2010 Thyroid hormone receptors regulate adipogenesis and carcinogenesis via cross-talk signaling with peroxisome proliferator-activated receptors. Journal of Molecular Endocrinology 44 143-154. (doi:10.1677/JME-09-0107)

Madsen L, Petersen RK, Sorensen MB, Jorgensen C, Hallenborg P, Pridal L, Fleckner J, Amri E, Krieg P, Furstenberger G et al. 2003 Adipocyte differentiation of 3T3-L1 preadipocytes is dependent on lipoxygenase activity during the initial stages of the differentiation process. Biochemical Journal $\mathbf{3 7 5}$ 539-549. (doi:10.1042/BJ20030503)

Marimuthu A, Feng W, Tagami T, Nguyen H, Jameson JL, Fletterick RJ, Baxter JD \& West BL 2002 TR surfaces and conformations required to bind nuclear receptor corepressor. Molecular Endocrinology 16 271-286. (doi:10.1210/me.16.2.271) 
Masugi J, Tamori Y, Mori H, Koike T \& Kasuga M 2000 Inhibitory effect of a proline-to-alanine substitution at codon 12 of peroxisome proliferator-activated receptor-gamma 2 on thiazolidinedioneinduced adipogenesis. Biochemical and Biophysical Research Communications 268 178-182. (doi:10.1006/bbrc.2000.2096)

Metivier R, Petit FG, Valotaire Y \& Pakdel F 2000 Function of $\mathrm{N}$-terminal transactivation domain of the estrogen receptor requires a potential alpha-helical structure and is negatively regulated by the A domain. Molecular Endocrinology 14 1849-1871. (doi:10.1210/me.14.11.1849)

Metivier R, Penot G, Flouriot G \& Pakdel F 2001 Synergism between ERalpha transactivation function 1 (AF-1) and AF-2 mediated by steroid receptor coactivator protein-1: requirement for the AF-1 alpha-helical core and for a direct interaction between the $\mathrm{N}$ - and C-terminal domains. Molecular Endocrinology 15 1953-1970. (doi:10.1210/me.15.11.1953)

Michalik L, Auwerx J, Berger JP, Chatterjee VK, Glass CK, Gonzalez FJ, Grimaldi PA, Kadowaki T, Lazar MA, O’Rahilly S et al. 2006 International Union of Pharmacology. LXI. Peroxisome proliferator-activated receptors. Pharmacological Reviews $\mathbf{5 8}$ 726-741. (doi:10.1124/pr.58.4.5)

Nugent C, Prins JB, Whitehead JP, Savage D, Wentworth JM, Chatterjee VK \& O'Rahilly S 2001 Potentiation of glucose uptake in 3T3-L1 adipocytes by PPAR gamma agonists is maintained in cells expressing a PPAR gamma dominantnegative mutant: evidence for selectivity in the downstream responses to PPAR gamma activation. Molecular Endocrinology 15 1729-1738. (doi:10.1210/me.15.10.1729)

Ohshima T, Koga H \& Shimotohno K 2004 Transcriptional activity of peroxisome proliferator-activated receptor gamma is modulated by SUMO-1 modification. Journal of Biological Chemistry 279 29551-29557. (doi:10.1074/jbc.M403866200)

Park Y, Freedman BD, Lee EJ, Park S \& Jameson JL 2003 A dominant negative PPARgamma mutant shows altered cofactor recruitment and inhibits adipogenesis in 3T3-L1 cells. Diabetologia 46 365-377. (doi:10.1007/s00125-0031177-6)

Perissi V \& Rosenfeld MG 2005 Controlling nuclear receptors: the circular logic of cofactor cycles. Nature Reviews. Molecular Cell Biology 6 542-554. (doi:10.1038/nrm1680)

Picard F, Kurtev M, Chung N, Topark-Ngarm A, Senawong T, Machado De Oliveira R, Leid M, McBurney MW \& Guarente L 2004 Sirt1 promotes fat mobilization in white adipocytes by repressing PPAR-gamma. Nature 429 771-776. (doi:10.1038/ nature02583)

Pippal JB \& Fuller PJ 2008 Structure-function relationships in the mineralocorticoid receptor. Journal of Molecular Endocrinology 41 405-413. (doi:10.1677/JME-08-0093)

Rangwala SM, Rhoades B, Shapiro JS, Rich AS, Kim JK, Shulman GI, Kaestner KH \& Lazar MA 2003 Genetic modulation of PPARgamma phosphorylation regulates insulin sensitivity. Developmental Cell 5 657-663. (doi:10.1016/S1534-5807(03) 00274-0)

Refetoff S, Weiss RE \& Usala SJ 1993 The syndromes of resistance to thyroid hormone. Endocrine Reviews 14 348-399. (doi:10. 1210/edrv-14-3-348)

Samuels HH, Stanley F \& Casanova J 1979 Depletion of L-3,5,3'triiodothyronine and L-thyroxine in euthyroid calf serum for use in cell culture studies of the action of thyroid hormone. Endocrinology 105 80-85. (doi:10.1210/endo-105-1-80)

Sasaki S, Nakamura H, Tagami T, Miyoshi Y \& Nakao K 1995 Functional properties of a mutant T3 receptor beta (R338W) identified in a subject with pituitary resistance to thyroid hormone. Molecular and Cellular Endocrinology 113 109-117. (doi:10.1016/0303-7207(95)03621-D)

Sasaki S, Lesoon-Wood LA, Dey A, Kuwata T, Weintraub BD, Humphrey G, Yang WM, Seto E, Yen PM, Howard BH et al. 1999
Ligand-induced recruitment of a histone deacetylase in the negative-feedback regulation of the thyrotropin beta gene. EMBO Journal 18 5389-5398. (doi:10.1093/emboj/18.19.5389)

Savage DB, Tan GD, Acerini CL, Jebb SA, Agostini M, Gurnell M, Williams RL, Umpleby AM, Thomas EL, Bell JD et al. 2003 Human metabolic syndrome resulting from dominant-negative mutations in the nuclear receptor peroxisome proliferatoractivated receptor-gamma. Diabetes 52 910-917. (doi:10.2337/ diabetes.52.4.910)

Semple RK, Chatterjee VK \& O'Rahilly S 2006 PPARgamma and human metabolic disease. Journal of Clinical Investigation 116 581-589. (doi:10.1172/JCI28003)

Shao D, Rangwala SM, Bailey ST, Krakow SL, Reginato MJ \& Lazar MA 1998 Interdomain communication regulating ligand binding by PPAR-gamma. Nature 396 377-380. (doi:10.1038/24634)

Shi Y, Hon M \& Evans RM 2002 The peroxisome proliferatoractivated receptor delta, an integrator of transcriptional repression and nuclear receptor signaling. PNAS $\quad \mathbf{9 9}$ 2613-2618. (doi:10.1073/pnas.052707099)

Stanley TB, Leesnitzer LM, Montana VG, Galardi CM, Lambert MH, Holt JA, Xu HE, Moore LB, Blanchard SG \& Stimmel JB 2003 Subtype specific effects of peroxisome proliferatoractivated receptor ligands on corepressor affinity. Biochemistry 42 9278-9287. (doi:10.1021/bi034472c)

Tachibana K, Kobayashi Y, Tanaka T, Tagami M, Sugiyama A, Katayama T, Ueda C, Yamasaki D, Ishimoto K, Sumitomo M et al. 2005 Gene expression profiling of potential peroxisome proliferator-activated receptor (PPAR) target genes in human hepatoblastoma cell lines inducibly expressing different PPAR isoforms. Nuclear Receptor 3 3. (doi:10.1186/1478-1336-3-3)

Tzameli I, Fang H, Ollero M, Shi H, Hamm JK, Kievit P, Hollenberg AN \& Flier JS 2004 Regulated production of a peroxisome proliferator-activated receptor-gamma ligand during an early phase of adipocyte differentiation in 3T3-L1 adipocytes. Journal of Biological Chemistry 279 36093-36102. (doi:10.1074/jbc.M405346200)

Wang LH, Yang XY, Zhang X, Huang J, Hou J, Li J, Xiong H, Mihalic K, Zhu H, Xiao W et al. 2004 Transcriptional inactivation of STAT3 by PPARgamma suppresses IL-6-responsive multiple myeloma cells. Immunity 20 205-218. (doi:10. 1016/S1074-7613(04)00030-5)

Werman A, Hollenberg A, Solanes G, Bjorbaek C, Vidal-Puig AJ \& Flier JS 1997 Ligand-independent activation domain in the N terminus of peroxisome proliferator-activated receptor gamma (PPARgamma). Differential activity of PPARgammal and -2 isoforms and influence of insulin. Journal of Biological Chemistry 272 20230-20235. (doi:10.1074/jbc.272.32.20230)

Winrow CJ, Kassam A, Miyata KS, Marcus SL, Hunter J, Capone JP \& Rachubinski RA 1996 Interplay of the peroxisome proliferator-activated receptor and the thyroid hormone receptorsignaling pathways in regulating peroxisome proliferatorresponsive genes. Annals of the New York Academy of Sciences 804 214-230. (doi:10.1111/j.1749-6632.1996.tb18618.x)

Xu HE, Stanley TB, Montana VG, Lambert MH, Shearer BG, Cobb JE, McKee DD, Galardi CM, Plunket KD, Nolte RT et al. 2002 Structural basis for antagonist-mediated recruitment of nuclear co-repressors by PPARalpha. Nature 415 813-817. (doi:10.1038/ 415813a)

Yamashita D, Yamaguchi T, Shimizu M, Nakata N, Hirose F \& Osumi T 2004 The transactivating function of peroxisome proliferator-activated receptor gamma is negatively regulated by SUMO conjugation in the amino-terminal domain. Genes to Cells 9 1017-1029. (doi:10.1111/j.1365-2443.2004.00786.x)

Yang Z, Hong SH \& Privalsky ML 1999 Transcriptional antirepression. Thyroid hormone receptor beta-2 recruits SMRT corepressor but interferes with subsequent assembly of a functional corepressor complex. Journal of Biological Chemistry 274 37131-37138. (doi:10.1074/jbc.274.52.37131) 
Yano M, Matsumura T, Senokuchi T, Ishii N, Murata Y, Taketa K, Motoshima H, Taguchi T, Sonoda K, Kukidome D et al. 2007 Statins activate peroxisome proliferator-activated receptor gamma through extracellular signal-regulated kinase $1 / 2$ and p38 mitogen-activated protein kinase-dependent cyclooxygenase-2 expression in macrophages. Circulation Research 100 1442-1451. (doi:10.1161/01.RES.0000268411.49545.9c)

Yoh SM, Chatterjee VK \& Privalsky ML 1997 Thyroid hormone resistance syndrome manifests as an aberrant interaction between mutant T3 receptors and transcriptional corepressors. Molecular Endocrinology 11 470-480. (doi:10.1210/me.11.4.470)

Yu C, Markan K, Temple KA, Deplewski D, Brady MJ \& Cohen RN 2005 The nuclear receptor corepressors NCoR and SMRT decrease peroxisome proliferator-activated receptor gamma transcriptional activity and repress 3T3-L1 adipogenesis. Journal of Biological Chemistry 280 13600-13605. (doi:10.1074/ jbc.M409468200)

Zamir I, Zhang J \& Lazar MA 1997 Stoichiometric and steric principles governing repression by nuclear hormone receptors. Genes and Development 11 835-846. (doi:10.1101/gad.11.7.835)

Zhang J, Hu X \& Lazar MA 1999 A novel role for helix 12 of retinoid $\mathrm{X}$ receptor in regulating repression. Molecular and Cellular Biology 19 6448-6457.

Received in final form 9 June 2010

Accepted 29 June 2010

Made available online as an Accepted Preprint 29 June 2010 